\title{
Expanding understanding of optical variability in Lake Superior with a 4-year dataset
}

\author{
Colleen B. Mouw ${ }^{1}$, Audrey B. Ciochetto ${ }^{1}$, Brice Grunert ${ }^{2}$, and Angela Yu ${ }^{2}$ \\ ${ }^{1}$ University of Rhode Island, Graduate School of Oceanography, 215 South Ferry Road, \\ Narragansett, RI 02882, USA \\ ${ }^{2}$ Michigan Technological University, 1400 Townsend Drive, Houghton, MI 49931, USA \\ Correspondence to: Colleen B. Mouw (cmouw@uri.edu)
}

Received: 9 February 2017 - Discussion started: 13 February 2017

Revised: 15 June 2017 - Accepted: 16 June 2017 - Published: 25 July 2017

\begin{abstract}
Lake Superior is one of the largest freshwater lakes on our planet, but few optical observations have been made to allow for the development and validation of visible spectral satellite remote sensing products. The dataset described here focuses on coincidently observing inherent and apparent optical properties along with biogeochemical parameters. Specifically, we observe remote sensing reflectance, absorption, scattering, backscattering, attenuation, chlorophyll concentration, and suspended particulate matter over the ice-free months of 20132016. The dataset substantially increases the optical knowledge of the lake. In addition to visible spectral satellite algorithm development, the dataset is valuable for characterizing the variable light field, particle, phytoplankton, and colored dissolved organic matter distributions, and helpful in food web and carbon cycle investigations. The compiled data can be freely accessed at https://seabass.gsfc.nasa.gov/archive/URI/Mouw/LakeSuperior/.
\end{abstract}

\section{Introduction}

Lake Superior is the largest of the Laurentian Great Lakes; it is the largest lake on Earth in area and the third largest lake on Earth by volume. Direct observations of Lake Superior are rare for nearly half of the year due to the long winter climatic conditions in the region. In situ observations are scarce from November through April, and in many years October and May are also precluded as seasonal storms and ice coverage hinder ship-based observations for long periods of time. As such, remote sensing is an important observational platform for observing the lake.

Remote sensing of the inland and coastal waters requires continued investment for in situ sampling to fully capture the dynamic range of parameter values and shifting relationships due to responses to climate change (Dierssen, 2010), anthropogenic stress, and invasive species (Mouw et al., 2015). Remote sensing efforts on the lake initially focused on estimating chlorophyll concentration with band-ratio algorithms (Budd and Warrington, 2004; Li et al., 2004) and met with limited success. More recently, Mouw et al. (2013) evaluated a variety of semi-analytical algorithms to identify the best performing for refinement. They found that the retrieval of chlorophyll concentration was not possible via inversion since errors in derived colored dissolved organic matter (CDOM) absorption were greater than the total contribution of phytoplankton to the overall absorption budget. However, they did demonstrate success in retrieving absorption due to CDOM. In light of the challenge of retrieving chlorophyll concentration, Trochta et al. (2015) classified remote sensing reflectance spectra into optical water types and connected the spatial and temporal variability in the water types to the physical processes of the lake.

In situ observations are an essential component of remote sensing satellite algorithm development and validation. When Mouw et al. (2013) completed their evaluation of algorithms, there were only eight stations with coincident observations of radiometry, absorption, and scattering for Lake Superior (Peng et al., 2009; Effler et al., 2010; O'Donnell et al., 2013). To enable the continued development of remote sensing algorithms for Lake Superior, a greater investment in optical observations was needed. Here we describe a dataset of coincident inherent and apparent optical prop- 

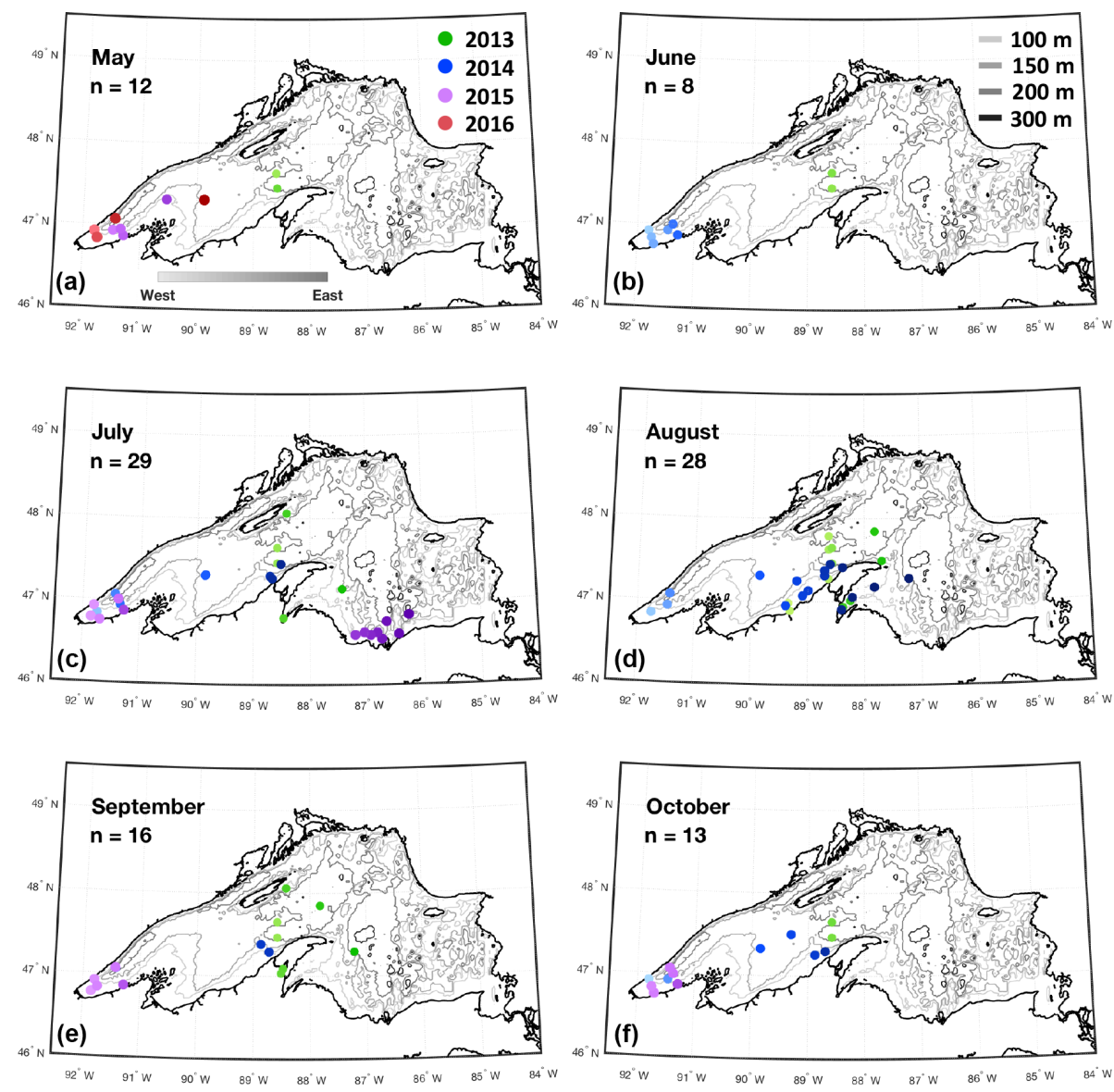

Figure 1. Station locations for the Lake Superior dataset sampled during 2013-2016 and grouped by month. The locations are colored by year and shaded by longitude from dark to light running east to west as shown in the legend (a). Depth contours are shown in gray.

erties collected throughout Lake Superior over the ice-free months of 2013 to 2016. Inherent optical properties (IOPs; i.e., absorption and scattering or backscattering) depend on in-water dissolved and particulate constituents, while apparent optical properties (AOPs; i.e., reflectance and attenuation) are dependent on both in-water constituents and the ambient light field. Collectively, these properties include remote sensing reflectance, absorption, scattering, backscattering, attenuation, pigment concentrations, and total suspended matter. Beyond satellite algorithm development, the dataset is valuable for characterizing the variable light field, particle, phytoplankton, and colored dissolved organic matter distributions, and helpful in food web and carbon cycle investigations.

\section{Data and methodology}

\subsection{Study site}

Containing approximately $10 \%$ of the Earth's surface freshwater, Lake Superior (Fig. 1) is the largest freshwater body on the planet in area $\left(8.21 \times 10^{4} \mathrm{~km}^{2}\right)$ and the third largest by volume $\left(1.21 \times 10^{4} \mathrm{~km}^{3}\right)$. The cold temperatures and low nutrient concentrations of Lake Superior (Sterner, 2011), compared to the other Laurentian Great Lakes, result in oligotrophic conditions (e.g., Matheson and Munawar, 1978; Munawar and Munawar, 1973; Weller, 1978; Barbiero and Tuchman, 2001) with low primary production (Sterner, 2010) and low species richness (Hubbs and Lagler, 2004). Superior is the fastest warming of all the Great Lakes (Mason et al., 2016), with summer surface temperatures rising faster than the temperature of the surrounding atmosphere (Austin and Allen, 2011; Austin and Colman, 2007; Lenters, 2004). This trajectory puts Lake Superior close to the upper range of global lake warming trends (O'Reilly et al., 2015). These warming trends impact the lake's energy balance, hydrology, ice cover, and mixing dynamics, which in turn impacts biotic and biogeochemical responses. The previous and limited optical observations of Lake Superior reveal that light absorption is dominated by colored dissolved organic matter $(\mathrm{CDOM} ; \geq 75 \%$ of the total absorption at $440 \mathrm{~nm}$; Effler et al., 2010) and the majority of the backscattering in the lake is attributed to organic rather than minerogenic sources (Peng et al., 2009). 


\subsection{In situ optical observations}

Optical and biogeochemical data were collected in Lake Superior during the ice-free months (May-October) of 2013 through 2016 (Fig. 1). The dataset consists of a full suite of coincident IOPs and AOPs. Observed IOPs include absorption due to water itself $\left(a_{\mathrm{w}}(\lambda), \mathrm{m}^{-1}\right)$, phytoplankton $\left(a_{\mathrm{ph}}(\lambda)\right.$, $\left.\mathrm{m}^{-1}\right)$, non-algal particles $\left(a_{\mathrm{NAP}}(\lambda), \mathrm{m}^{-1}\right)$, colored dissolved organic matter $\left(a_{\mathrm{CDOM}}(\lambda), \mathrm{m}^{-1}\right)$, and backscattering due to water itself $\left(b_{\mathrm{bw}}(\lambda), \mathrm{m}^{-1}\right)$ and particles $\left(b_{\mathrm{bp}}(\lambda), \mathrm{m}^{-1}\right)$. Observed AOPs include downwelling and surface irradiance $\left(E_{\mathrm{d}}(\lambda)\right.$ and $E_{\mathrm{S}}(\lambda)$, respectively; $\left.\mu \mathrm{W} \mathrm{cm}^{-2}\right)$ along with upwelling radiance $\left(L_{\mathrm{u}}(\lambda), \mu \mathrm{W} \mathrm{cm}{ }^{-2} \mathrm{sr}^{-1}\right)$, which were used to retrieve remote sensing reflectance $\left(R_{\mathrm{rs}}(\lambda), \mathrm{sr}^{-1}\right)$ and the downwelling and upwelling diffuse attenuation coefficients $\left(K_{\mathrm{d}}(\lambda)\right.$ and $K_{\mathrm{u}}(\lambda), \mathrm{m}^{-1}$, respectively). A summary of the parameters and units can be found in Table 1.

\subsubsection{Apparent optical properties}

Radiometric measurements were made with three HyperOCR spectral radiometers (Satlantic Inc.) that measure between 350 and $800 \mathrm{~nm}$ with approximately $3 \mathrm{~nm}$ of resolution (137 total wavelengths). In-water $E_{\mathrm{d}}(\lambda)$ and $L_{\mathrm{u}}(\lambda) \mathrm{Hy}-$ perOCR sensors were attached to a free-falling Profiler II frame (Satlantic Inc.), while the $E_{\mathrm{s}}(\lambda)$ sensor was mounted on top of the ship to allow for the correction of the other measurements due to changing sky conditions. At each station, the system was deployed for three cast types: surface, multi-profile, and full profile. To characterize the air-water interface, a floatation collar on the profiler frame enabled the continuous measurement of $L_{\mathrm{u}}(\lambda)$ approximately $20 \mathrm{~cm}$ below the water surface for $5 \mathrm{~min}$ (surface profile). The flotation collar was removed and the profiler was then deployed in free-fall mode, measuring five consecutive profiles from the surface to $10 \mathrm{~m}$ to characterize the near-surface light field (multi-profile). Finally, the profiler was allowed to free fall to the $1 \%$ light level or to within $10 \mathrm{~m}$ of the bottom, whichever was shallower (full profile).

All methods and analysis follow the NASA ocean optics protocols for satellite ocean color sensor validation (Mueller et al., 2003a). $E_{\mathrm{d}}(\lambda), L_{\mathrm{u}}(\lambda)$, and $E_{\mathrm{s}}(\lambda)$ were dark corrected and quality controlled to exclude data collected at high instrument tilt $\left(>4^{\circ}\right) . E_{\mathrm{S}}(\lambda)$ was smoothed over a $15 \mathrm{~s}$ interval and $E_{\mathrm{d}}(t, \lambda)$ and $L_{\mathrm{u}}(t, \lambda)$ were normalized to the ratio of $E_{\mathrm{S}}\left(t_{0}, \lambda\right) / E_{\mathrm{S}}(t, \lambda)$ to account for variability in surface irradiance throughout each profile measurement. Data from surface, multi-profiles, and full profiles were binned to $1 \mathrm{~m}$.

Using binned multi-profile data, normalized $E_{\mathrm{d}}(z, \lambda)$ and $L_{\mathrm{u}}(z, \lambda)$ were natural-log transformed and fit as a function of depth to retrieve the attenuation coefficients $K_{\mathrm{d}}(\lambda)$ and $K_{\mathrm{u}}(\lambda)$, respectively (Smith and Baker, 1984, 1986):

$\ln [X(z, \lambda)]=\ln \left[X\left(z_{m}, \lambda\right)\right]-\left(z-z_{m}\right) K\left(z_{m}\right)$,
Table 1. Summary of parameters.

\begin{tabular}{ll}
\hline & \multicolumn{1}{c}{ Found in dataset } \\
\hline$a_{\mathrm{nw}}(\lambda)$ & spectral non-water absorption $\left(\mathrm{m}^{-1}\right)$ \\
$a_{\mathrm{p}}(\lambda)$ & spectral particulate absorption $\left(\mathrm{m}^{-1}\right)$ \\
$a_{\mathrm{ph}}(\lambda)$ & spectral phytoplankton absorption $\left(\mathrm{m}^{-1}\right)$ \\
$a_{\mathrm{NAP}}(\lambda)$ & spectral non-algal particle absorption $\left(\mathrm{m}^{-1}\right)$ \\
$a_{\mathrm{CDOM}}(\lambda)$ & spectral colored dissolved organic matter absorption $\left(\mathrm{m}^{-1}\right)$ \\
$b_{\mathrm{b}}(\lambda)$ & spectral total backscattering $\left(\mathrm{m}^{-1}\right)$ \\
$b_{\mathrm{bp}}(\lambda)$ & spectral particulate backscattering $\left(\mathrm{m}^{-1}\right)$ \\
$c_{\mathrm{nw}}(\lambda)$ & spectral non-water attenuation $\left(\mathrm{m}^{-1}\right)$ \\
$E_{\mathrm{d}}(\lambda)$ & downwelling irradiance $\left(\mu \mathrm{W} \mathrm{cm}^{-2}\right)$ \\
$E_{\mathrm{S}}(\lambda)$ & surface irradiance $\left(\mu \mathrm{W} \mathrm{cm}^{-2}\right)$ \\
$L_{\mathrm{u}}(\lambda)$ & upwelling radiance $\left(\mu \mathrm{W} \mathrm{cm}^{-2} \mathrm{sr}^{-1}\right)$ \\
{$[\mathrm{Chl}]$} & chlorophyll $a$ concentration $\left(\mathrm{mg} \mathrm{m}^{-3}\right)$ \\
{$[\mathrm{Phaeo}]$} & phaeopigment concentration $\left(\mathrm{mg} \mathrm{m}^{-3}\right)$ \\
$\mathrm{SPM}$ & total suspended particulate matter $\left(\mathrm{mg} \mathrm{L}^{-1}\right)$ \\
$\mathrm{SPM}_{\mathrm{i}}$ & inorganic suspended particulate matter $\left(\mathrm{mg} \mathrm{L}^{-1}\right)$ \\
$\mathrm{SPM}$ & organic suspended particulate matter $\left(\mathrm{mg} \mathrm{L} \mathrm{L}^{-1}\right)$ \\
\hline & $\quad$ Not in dataset but used in calculations \\
\hline$a_{\mathrm{t}}(\lambda)$ & spectral total absorption $\left(\mathrm{m}^{-1}\right)$ \\
$a_{\mathrm{w}}(\lambda)$ & spectral water absorption $\left(\mathrm{m}^{-1}\right)$ \\
$b_{\mathrm{t}}(\lambda)$ & spectral total scattering $\left(\mathrm{m}^{-1}\right)$ \\
$b_{\mathrm{W}}(\lambda)$ & spectral water scattering $\left(\mathrm{m}^{-1}\right)$ \\
$b_{\mathrm{bw}}(\lambda)$ & spectral water backscattering $\left(\mathrm{m}^{-1}\right)$ \\
$c_{\mathrm{t}}(\lambda)$ & spectral total attenuation $\left(\mathrm{m}^{-1}\right)$ \\
$L_{\mathrm{w}}(\lambda)$ & water-leaving radiance $\left(\mu \mathrm{W} \mathrm{cm}^{-2} \mathrm{sr}^{-1}\right)$ \\
$R_{\mathrm{rs}}(\lambda)$ & spectral remote sensing reflectance $\left(\mathrm{sr}^{-1}\right)$ \\
$R(\lambda)$ & spectral reflectance $\left(\mathrm{sr}^{-1}\right)$ \\
$K_{\mathrm{d}}(\lambda)$ & spectral downwelling diffuse attenuation coefficient $\left(\mathrm{m}^{-1}\right)$ \\
$K_{\mathrm{u}}(\lambda)$ & spectral upwelling diffuse attenuation coefficient $\left(\mathrm{m}^{-1}\right)$ \\
\hline &
\end{tabular}

where $X$ is either $E_{\mathrm{d}}$ or $L_{\mathrm{u}}, z$ is depth, $z_{m}$ is a central reference depth, and $K$ is either $K_{\mathrm{d}}$ or $K_{\mathrm{u}}$. This method assumes that $K$ is uniform across the depth interval used in the regression. For the majority of the Lake Superior dataset, the upper $8 \mathrm{~m}$ of the water column was typically utilized for the retrieval of $K$, as recommended by Smith and Baker (1984, 1986). However, some locations near river outflows show shallow layers with distinct optical changes, reducing the uniform depth interval to about $5 \mathrm{~m}$.

Using $K$-regression results, $E_{\mathrm{d}}(\lambda)$ and $L_{\mathrm{u}}(\lambda)$ were propagated to just below the surface $\left(E_{\mathrm{d}}\left(0^{-}, \lambda\right)\right.$ and $\left.L_{\mathrm{u}}\left(0^{-}, \lambda\right)\right)$. Water-leaving radiance $\left(L_{\mathrm{w}}(\lambda)\right)$ was calculated from $L_{\mathrm{u}}\left(0^{-}\right.$, $\lambda$ ) according to

$L_{\mathrm{w}}(\lambda)=0.543 \cdot L_{\mathrm{u}}\left(0^{-} \lambda\right)$,

where 0.543 accounts for the net effects of surface reflectance and the refractive index of seawater as light travels across the sea-air interface (Lee et al., 2002; Mobley, 1994). $R_{\mathrm{rs}}(\lambda)$ was then retrieved as

$R_{\mathrm{rs}}(\lambda)=\frac{L_{\mathrm{W}}(\lambda)}{E_{\mathrm{s}}(\lambda)}$. 


\subsubsection{Inherent optical properties}

IOPs were collected via a vertically profiled bio-optical package that measures absorption, attenuation (Wetlabs AC-S), and backscattering (Wetlabs ECO-BB9) along with concurrent temperature, salinity (Sea-Bird CTD 37-SI), and fluorometeric chlorophyll $a$ (Wetlabs ECO-FL3). All methods and analysis followed the NASA ocean optics protocols for satellite ocean color sensor validation (Mueller et al., 2003b). The ECO-FL3 was calibrated on a yearly basis, regressing in situ chlorophyll $a$ fluorescence with an extracted chlorophyll $a$ concentration ([Chl]; $\mathrm{mg} \mathrm{m}^{-3}$ ) derived from discrete field samples.

Total absorption and attenuation $\left(a_{\mathrm{t}}(\lambda)\right.$ and $c_{\mathrm{t}}(\lambda), \mathrm{m}^{-1}$, respectively) were resolved at 81 wavelengths between 400 and $750 \mathrm{~nm}$. CTD data were used to correct $a_{\mathrm{t}}(\lambda)$ and $c_{\mathrm{t}}(\lambda)$ for temperature and salinity effects using the coefficients of Sullivan et al. (2006). The AC-S was calibrated before and after each cruise with ultrapure water (ion, particle, and bubble free). This pure-water absorption and attenuation $\left(a_{\mathrm{w}}(\lambda)\right.$ and $\left.c_{\mathrm{W}}(\lambda)\right)$ was subtracted to retrieve the contribution of nonwater components $\left(a_{\mathrm{nw}}(\lambda)\right.$ and $\left.c_{\mathrm{nw}}(\lambda)\right)$. Data were corrected for scattering effects using the proportional method of Zaneveld et al. (1994). The bio-optical package was deployed for two successive casts: total and filtered. For the filtered cast, the AC-S intake was fit with a $0.2 \mu \mathrm{m}$ filter (Pall; Maxi Capsule Filter 12112) to allow for the measurement of dissolved components only $\left(a_{\mathrm{CDOM}}(\lambda), \mathrm{m}^{-1}\right)$. During deployment, the package was lowered at $0.2 \mathrm{~m} \mathrm{~s}^{-1}$ or as slow as possible. All data were binned to $1 \mathrm{~m}$ during analysis. Particulate absorption $\left(a_{\mathrm{p}}(\lambda), \mathrm{m}^{-1}\right)$ was retrieved by the difference between the total and filtered casts $\left.(=] a_{\mathrm{nw}}(\lambda)-a_{\mathrm{CDOM}}(\lambda)\right)$. Pure-water absorption and attenuation as measured by Pope and Fry (1997) was then added to $a_{\mathrm{nw}}(\lambda)$ and $c_{\mathrm{nw}}(\lambda)$ to return to total values.

The ECO-BB9 measures the volume scattering coefficient $\left(\beta_{\mathrm{t}}, \mathrm{m}^{-1} \mathrm{sr}^{-1}\right)$ for an acceptance angle of $124^{\circ}$ at nine wavelengths: 412, 440, 488, 510, 532, 595, 650, 676, and $715 \mathrm{~nm}$. Instrument calibration was performed at Wetlabs in Narragansett, RI using $0.1 \mu \mathrm{m}$ NIST-traceable beads (Thermo Fisher Scientific 3100A; bead lot number 43585) at $9^{\circ} \mathrm{C}$ following the procedure of Sullivan et al. (2013). Processed AC$\mathrm{S}$ measurements were interpolated to BB9 wavelengths and backscattering data were corrected for absorption:

$\beta=\beta_{\mathrm{t}} e^{\left(l-a_{\mathrm{t}}\right)}$,

where $l$ is the pathlength of the BB9 $(=0.0391 \mathrm{~m})$. The volume scattering function $\left(\beta_{\mathrm{w}} ; \mathrm{m}^{-1} \mathrm{sr}^{-1}\right)$ and total scattering $\left(b_{\mathrm{w}} ; \mathrm{m}^{-1}\right)$ of pure water was retrieved from temperature and salinity measurements using the model of Zhang and $\mathrm{Hu}$ (2009). The backscattering of pure water $\left(b_{\mathrm{bw}} ; \mathrm{m}^{-1}\right)$ was considered half of total scattering $\left(=b_{\mathrm{w}} / 2\right)$. The volume scattering of the particulate fraction $\left(\beta_{\mathrm{p}} ; \mathrm{m}^{-1} \mathrm{sr}^{-1}\right)$ was then retrieved by difference $\left(=\beta-\beta_{\mathrm{w}}\right)$. Particulate backscatter- ing was calculated by taking the acceptance angle into account (Sullivan et al., 2013):

$b_{\mathrm{bp}}=2 \pi \chi \beta_{\mathrm{p}}$,

where $\chi=1.076$ for a $124^{\circ}$ measurement angle. Total backscattering $\left(b_{\mathrm{b}} ; \mathrm{m}^{-1}\right)$ was then retrieved as the sum of particulate and water components $\left(=b_{\mathrm{bp}}+b_{\mathrm{bw}}\right)$.

\subsection{Laboratory analysis of discrete water samples}

Whole water samples were taken from multiple depths representative of the surface $(5 \mathrm{~m})$ and at a mid-depth of the euphotic zone often coincident with the deep chlorophyll maximum if one was present (11-50 m). During well-mixed times of year, when a deep chlorophyll layer was not observed, samples are only taken in the surface layer. Collected water was stored in the dark on ice and was processed within $8 \mathrm{~h}$. Discrete water samples are used for determining [Chl], $a_{\mathrm{p}}(\lambda), a_{\mathrm{NAP}}(\lambda), a_{\mathrm{ph}}(\lambda), a_{\mathrm{CDOM}}(\lambda)$, and the organic and inorganic components of suspended particulate matter $\left(\mathrm{SPM}_{O}\right.$ and $\mathrm{SPM}_{\mathrm{I}}$, respectively; $\mathrm{mg} \mathrm{L}^{-1}$ ).

Samples for [Chl] and $a_{\mathrm{p}}(\lambda)$ were filtered in triplicate onto Whatman glass fiber filters (GF/F; $0.7 \mu \mathrm{m}$ nominal pore size), stored in liquid nitrogen while at sea, and moved to a $-80^{\circ} \mathrm{C}$ freezer in the lab until analysis. Samples for $a_{\mathrm{CDOM}}(\lambda)$ were filtered through an acid-washed $0.2 \mu \mathrm{m}$ membrane filter (Whatman; Nuclepore 111106) and the filtrate was stored in clear borosilicate bottles (Qorpak; GLC-01151) in a refrigerator until analysis. Directly prior to each cruise, borosilicate bottles were acid washed and muffled at $450{ }^{\circ} \mathrm{C}$ for $4 \mathrm{~h}$ to remove any potential contaminants.

Spectral CDOM, particulate, non-algal, and phytoplankton absorption were measured spectrophotometrically (PerkinElmer; Lambda 35 UV/Vis dual beam) for wavelengths between 300 and $800 \mathrm{~nm}$. Absorption of CDOM filtrate was measured in a $10 \mathrm{~cm}$ cuvette following the NASA ocean optics protocols (Mueller et al., 2003b) using a slit width of $2 \mathrm{~nm}$ and a scan rate of $240 \mathrm{~nm} \mathrm{~min}^{-1}$. For particulate and non-algal absorption, we followed the transmission-reflectance (T-R) method (Tassan and Ferrari, 2002; Lohrenz, 2000; Lohrenz et al., 2003) that utilizes an integrating sphere to correct measurements for the contribution of scattering. Daily blanks were prepared by filtering $25 \mathrm{~mL}$ of ultrapure water (ion and particle free) onto a $\mathrm{GF} / \mathrm{F}$ and used to normalize T-R data during analysis. Filters were placed on a quartz slide at the entrance (transmittance) and exit (reflectance) of the sphere and scanned at a speed of $120 \mathrm{~nm} \mathrm{~min}^{-1}$ with a slit width of $2 \mathrm{~nm}$ both before $\left(a_{\mathrm{p}}\right)$ and after $\left(a_{\mathrm{NAP}}\right)$ exposure to sodium hypochlorite. It should be noted that while methanol extraction is common for this step in marine samples (Mitchell et al., 2003), the use of sodium hypochlorite is preferred in freshwater due to the resistance of some cyanobacterial pigments to methanol extraction (Porra, 1990; Binding et al., 2008). The difference 
between these measurements is the contribution due to phytoplankton $\left(a_{\mathrm{ph}}=a_{\mathrm{p}}-a_{\mathrm{NAP}}\right)$. Absorption is calculated following Lohrenz (2000).

Extracted [Chl] and phaeopigments were determined following the NASA ocean optics protocols (Trees et al., 2003) for both instrument calibration and sample analysis. Working in the dark, filtered samples were placed in prechilled $90 \%$ acetone and sonicated for 20 to 30 s to break cells open. Sonicated samples were stored in the freezer $\left(-20^{\circ} \mathrm{C}\right)$ and allowed to extract for $24 \mathrm{~h}$ prior to analysis. Samples were brought to room temperature and centrifuged at 3000 RPM for $20 \mathrm{~min}$ to remove filter particulates. Fluorescence was measured before and after the addition of $50 \mu \mathrm{L}$ of $10 \% \mathrm{HCl}$ on a Turner Designs 10AU fluorometer (optical kit 10-037R). Blanks of $90 \%$ acetone were measured daily. The fluorometer was calibrated yearly with a dilution series of pure chlorophyll $a$ (Sigma-Aldrich; C6144) extracted in $90 \%$ acetone. Field samples were analyzed within 6 months of fluorometer calibration. [Chl] was retrieved from blank-corrected fluorescence as

$[\mathrm{Chl}]=\frac{\left(F_{\mathrm{b}}-F_{\mathrm{a}}\right)}{F_{\mathrm{R}}} \cdot \frac{\tau}{\tau-1} \cdot \frac{V_{\mathrm{S}}}{V_{\mathrm{F}}}$,

and phaeopigment concentration ([Phaeo], $\mathrm{mg} \mathrm{m}^{-3}$ ) was calculated as

$[$ Phaeo $]=\frac{\left(F_{\mathrm{a}} \tau-F_{\mathrm{b}}\right)}{F_{\mathrm{R}}} \cdot \frac{\tau}{\tau-1} \cdot \frac{V_{\mathrm{S}}}{V_{\mathrm{F}}}$,

where $F_{\mathrm{b}}$ and $F_{\mathrm{a}}(\mathrm{FSU})$ are the fluorescence measured before and after acidification, respectively, $F_{\mathrm{R}}\left(\mathrm{FSU}\left(\mathrm{mg} \mathrm{m}^{-3}\right)^{-1}\right)$ is the slope of the fluorometer calibration, $\tau$ (unitless) is the acid ratio of the fluorometer calibration, and $V_{\mathrm{S}}$ and $V_{\mathrm{F}}(\mathrm{mL})$ are the volume of the solvent and filtered water sample, respectively.

Both organic and inorganic SPM were quantified following the methodology of APHA, AWWA, and WEF (2005) and the recommendations of Boss et al. (2009) and Woźinak et al. (2011). Whatman GF/F filters ( $47 \mathrm{~mm}$; $0.7 \mu \mathrm{m}$ pore size) were prepared by washing with $\sim 100 \mathrm{~mL}$ of ultrapure water to rinse away any loose glass fibers. They were then dried at $103-105^{\circ} \mathrm{C}$ for $1 \mathrm{~h}$, muffled at $550^{\circ} \mathrm{C}$ for $4 \mathrm{~h}$, and allowed to cool in a desiccator. Filters were pre-weighed on a high-precision balance $\left(W_{\mathrm{F}} ; \mathrm{mg}\right)$. Duplicate samples were filtered with a minimum of $3 \mathrm{~L}$ of collected water and stored at $-80^{\circ} \mathrm{C}$ until analysis. Samples were removed from the freezer, dried at $103-105^{\circ} \mathrm{C}$ for $1 \mathrm{~h}$, and placed in a desiccator to cool. Dried filters were then weighed within $2 \mathrm{~h}$ of removal from the oven $\left(W_{\mathrm{R}} ; \mathrm{mg}\right)$. Filters were muffled at $550{ }^{\circ} \mathrm{C}$ for $1 \mathrm{~h}$, returned to the desiccator to cool, and reweighed $\left(W_{\mathrm{I}} ; \mathrm{mg}\right)$. Total and inorganic SPM were retrieved as

$\mathrm{SPM}=\left(W_{\mathrm{R}}-W_{\mathrm{F}}\right) / V$,

$\mathrm{SPM}_{\mathrm{I}}=\left(W_{\mathrm{I}}-W_{\mathrm{F}}\right) / V$, where $V$ is the volume filtered $(\mathrm{L})$. The organic component can be retrieved by difference $\left(\mathrm{SPM}_{\mathrm{O}}=\mathrm{SPM}-\mathrm{SPM}_{\mathrm{I}}\right)$.

\section{Results}

Data were collected from 106 stations from May through October of 2013 to 2016. Collection was aimed at maximizing spatial and temporal variability and dynamic range. Thus, repeat stations were only found for six locations. The range, mean, and standard deviation for all parameters are reported in Table 2. Most of the observations were made in July $(n=29)$ and August $(n=28)$ but also show reasonable distribution in the early spring (May $n=12$; June $n=8$ ) and fall (September $n=16$; October $n=13$ ). Data were only collected in US waters; thus the Canadian waters encompassing the northern reaches of the lake were not observed. To some extent, the sampling locations were dependent on the home port of the research vessels. The western basin $(41 \%)$ and the central basin, near the Keweenaw Peninsula (41\%) of the lake, were well observed. The eastern basin was observed only during July 2015 and at a single site in July 2013, August 2014, and September 2013 (Fig. 1).

The lake is dimictic (Assel, 1986) and develops a strong thermocline and deep chlorophyll maximum (DCM; Barbiero and Tuchman, 2004) in the summer months. The water column was completely mixed in May and June in all years (Fig. 2a and b). A thermocline was evident in nearly all locations by July (Fig. 2c), becoming stronger and deeper in August (Fig. 2d). Depending on the location and year, the thermocline either deepened or shallowed in September and October, with evidence of a fully mixed water column in some locations in October (Fig. 2e and f). In the fluorometric [Chl] profiles shown in Fig. 2, [Chl] was slightly lower in the near-surface water in May and June due to fluorescence quenching when the water column was well mixed (Fig. $2 \mathrm{~g}$ and $\mathrm{h}$ ). When [Chl] was derived from absorption, the profiles were uniform at this time of year (not shown). The formation of a DCM follows the development of the thermocline. As the thermocline sets up in July, the DCM develops and becomes more pronounced and deeper in August as the thermocline deepens (Fig. 2i and j). The DCM was still evident in September, but became weaker in magnitude and began to shallow (Fig. 2k). By October, when the lake was beginning to become fully mixed, [Chl] remained low in the nearsurface waters and slightly elevated in mid-depths where the DCM was previously found (Fig. 2).

Discrete absorption samples partitioned into water, phytoplankton, non-algal particles, and CDOM display contributions from riverine inputs and broad lake processes near the surface and at mid-depth (Fig. 3). The St. Louis River enters Lake Superior in its western arm. Absorption was fairly evenly distributed there between water, phytoplankton, and CDOM, with some contributions of NAP in May. By June and July, the surface waters were dominated by CDOM and 
Table 2. Data product range, mean, and standard deviation for the entire dataset. Parameter definitions and units can be found in Table 1. Spectral data products are presented for the closest measurement to $443 \mathrm{~nm}$.

\begin{tabular}{|c|c|c|c|c|c|c|c|c|c|}
\hline & \multirow[b]{2}{*}{ Parameter } & \multicolumn{4}{|c|}{ Surface $(\leq 5 \mathrm{~m})$} & \multicolumn{4}{|c|}{ Mid-depth (10-50 m) } \\
\hline & & Min & Max & Mean & SD & Min & Max & Mean & SD \\
\hline \multirow{9}{*}{ 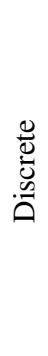 } & $a_{\mathrm{nw}}(443)$ & 0.063 & 9.704 & 1.150 & 1.302 & 0.077 & 1.916 & 0.868 & 0.645 \\
\hline & $a_{\mathrm{p}}(443)$ & 0.017 & 0.596 & 0.061 & 0.082 & 0.213 & 0.553 & 0.058 & 0.057 \\
\hline & $a_{\mathrm{ph}}(443)$ & 0.014 & 0.457 & 0.045 & 0.053 & 0.020 & 0.439 & 0.049 & 0.045 \\
\hline & $a_{\mathrm{NAP}}(443)$ & 0.001 & 0.203 & 0.015 & 0.032 & 0.001 & 0.114 & 0.008 & 0.013 \\
\hline & $a_{\mathrm{CDOM}}(443)$ & 0.025 & 2.211 & 0.185 & 0.355 & 0.039 & 1.827 & 0.112 & 0.204 \\
\hline & {$[\mathrm{Chl}]$} & 0.30 & 9.72 & 1.27 & 1.16 & 0.65 & 3.13 & 1.54 & 0.61 \\
\hline & SPM & 0.25 & 7.89 & 0.78 & 1.24 & 0.05 & 13.78 & 0.77 & 1.81 \\
\hline & $\mathrm{SPM}_{\mathrm{i}}$ & 0.18 & 1.54 & 0.40 & 0.22 & 0.05 & 1.57 & 0.40 & 0.22 \\
\hline & $\mathrm{SPM}_{\mathrm{O}}$ & 0.00 & 6.35 & 0.39 & 1.05 & 0.00 & 12.21 & 0.38 & 1.65 \\
\hline \multirow{12}{*}{$\frac{\frac{D}{0}}{\frac{D}{0}}$} & $a_{\mathrm{nw}}(441)$ & 0.049 & 1.485 & 0.201 & 0.227 & 0.072 & 1.204 & 0.169 & 0.116 \\
\hline & $a_{\mathrm{p}}(441)$ & 0.007 & 0.690 & 0.077 & 0.083 & 0.000 & 1.070 & 0.071 & 0.096 \\
\hline & $a_{\mathrm{CDOM}}(441)$ & 0.023 & 0.716 & 0.118 & 0.103 & 0.043 & 0.326 & 0.102 & 0.043 \\
\hline & $b_{\mathrm{b}}(440)$ & 0.0039 & 0.2906 & 0.0151 & 0.0307 & 0.0044 & 0.3560 & 0.0146 & 0.0337 \\
\hline & $b_{\mathrm{bp}}(440)$ & 0.0022 & 0.2889 & 0.0134 & 0.0307 & 0.0027 & 0.3543 & 0.0129 & 0.0337 \\
\hline & $c_{\mathrm{nw}}(444)$ & 0.205 & 10.200 & 0.699 & 1.049 & 0.1133 & 16.4248 & 0.680 & 1.336 \\
\hline & $E_{\mathrm{d}}(443)$ & 0.0157 & 121.1417 & 37.4051 & 27.8633 & 0.0000 & 45.3424 & 2.2060 & 2.4373 \\
\hline & $E_{\mathrm{S}}(442)$ & 4.7938 & 133.1492 & 78.8109 & 40.5818 & - & - & - & - \\
\hline & $L_{\mathrm{u}}(442)$ & 0.00046 & 0.6128 & 0.1812 & 0.1371 & 0.0000 & 0.2065 & 0.0103 & 0.0117 \\
\hline & $R_{\mathrm{rs}}(442)$ & 0.00022 & 0.0051 & 0.0023 & 0.0008 & - & - & - & - \\
\hline & $K_{\mathrm{d}}(442)$ & 0.0847 & 2.0759 & 0.2829 & 0.2712 & - & - & - & - \\
\hline & [Chl] & 0.00 & 7.21 & 0.87 & 0.95 & 0.00 & 4.26 & 1.40 & 0.44 \\
\hline
\end{tabular}
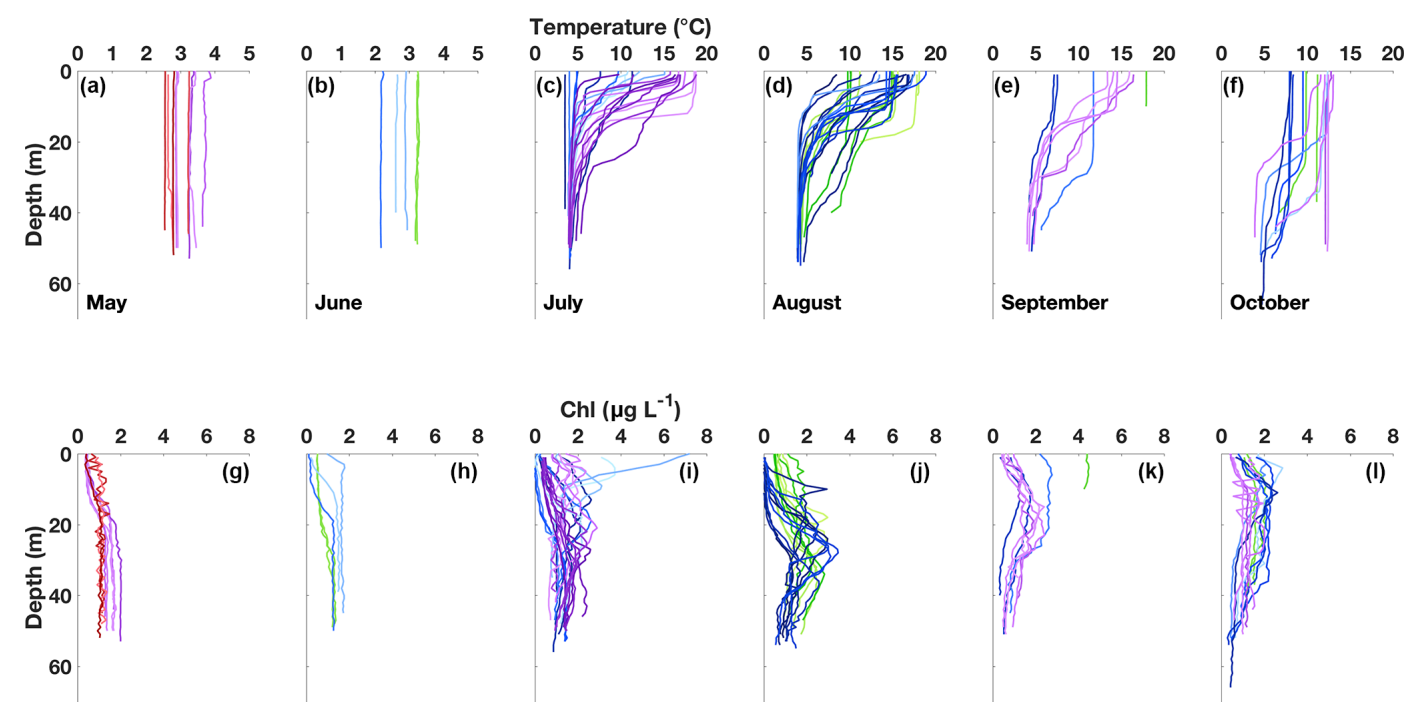

Figure 2. Profiles of temperature (a-f) and [Chl] retrieved from in situ fluorescence (g-l) for the Lake Superior dataset. The profiles are colored by year and shaded by longitude as in Fig. 1 . Data are binned by $1 \mathrm{~m}$. Note the compressed $x$-axis limits for temperature profiles in May and June (a, b). Throughout the region, water column stratification is not observed until July or even August (c, d) and is eroded in the fall (f). Absolute [Chl] levels are low throughout the lake, even during spring and summer months (g-l).

a growing contribution from phytoplankton. This was presumably due to the spring melt entering the lake. In August there was an overall decline in absorption as this is a time of lower river flow with a greater transition toward phytoplank- ton dominance in September and October when fall storms generate more runoff and the river serves as a nutrient delivery conduit to the lake (Fig. 3). The surface waters of the central region of the lake remained dominated by water year- 

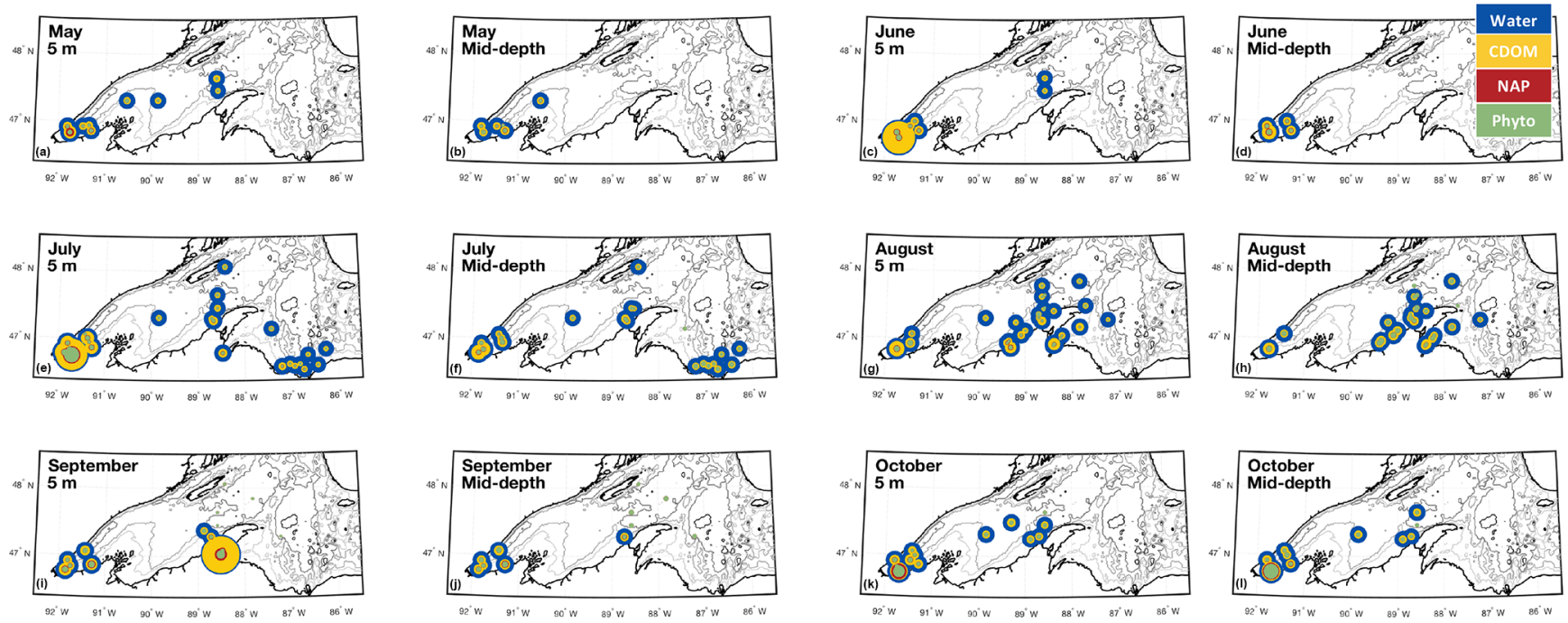

Figure 3. Absorption for discrete water samples taken at $5 \mathrm{~m}$ and mid-depth throughout Lake Superior grouped by month. The outer diameter for each station marker is relative to total absorption with the contribution of water, CDOM, non-algal particles, and phytoplankton indicated by the relative size of the concentric circles.

round with a significant CDOM contribution near the Ontonagon River outlet and within the Keweenaw Peninsula waterway that contains Portage Lake. Samples at mid-depth were not targeted when the water column was well mixed in May and June. The mid-depth becomes progressively dominated by phytoplankton between July and September as the DCM develops and declines. By October, surface and mid-depth absorption were similar (Fig. 3). Considering the absorption budget, CDOM was by far the largest contributor (50-80\%), followed by phytoplankton, while NAP made up a less than $15 \%$ contribution across all stations. Phytoplankton made up a greater percentage of mid-depth absorption, while CDOM was more variable in surface waters. NAP contributions were only slightly lower in the mid-depth (Fig. 4).

To display the spectral variability observed in the absorption budget, three stations were selected in different regions throughout the lake (Fig. 5). As $a_{\mathrm{CDOM}}(\lambda)$ absorbs most strongly in the ultraviolet and blue region of the spectrum, its contribution decreases exponentially with increasing wavelength. Phytoplankton also absorb strongly in the blue region of the spectrum, with a peak near $443 \mathrm{~nm}$ and a secondary peak at $687 \mathrm{~nm}$. While phytoplankton accounted for a larger proportion of absorption at mid-depth compared to the surface, they comprised $<50 \%$ of the total absorption budget in blue wavelengths at all depths (Fig. 5). NAP was a larger contributor in the surface, particularly for the sites near river outlets (Fig. 5a and c).

The particulate portion of absorption (NAP and phytoplankton) was further explored by $\mathrm{SPM}_{\mathrm{i}}$ and $\mathrm{SPM}_{\mathrm{o}}$. All nonphytoplankton particles are included in $a_{\mathrm{NAP}}(\lambda)$, while $\mathrm{SPM}_{\mathrm{i}}$ includes only minerogenic particles. Similar to absorption, the greatest SPM loads were found near the outlet of the St. Louis River with a magnitude varying with the season
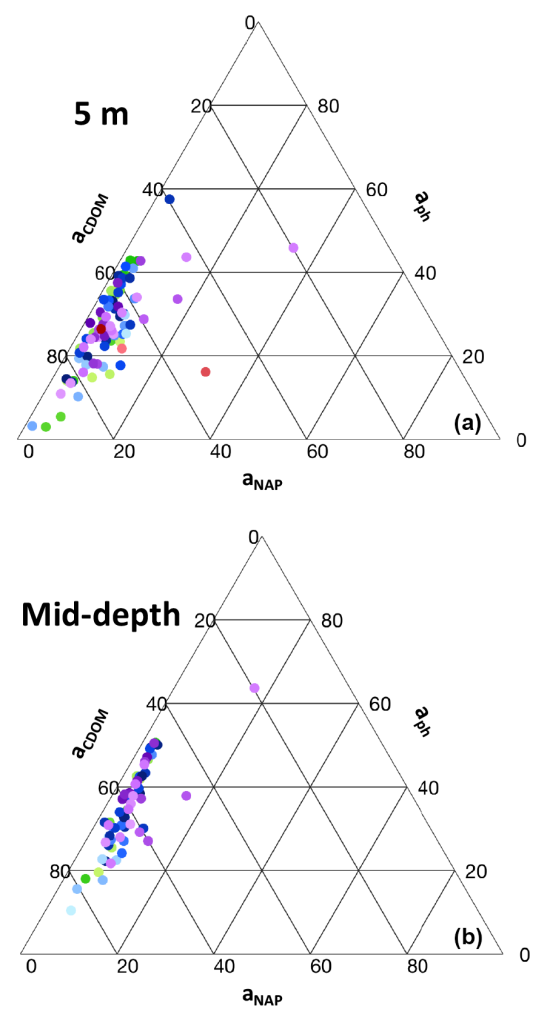

Figure 4. Ternary plots of the contribution of CDOM, non-algal particles, and phytoplankton to total non-water absorption at $443 \mathrm{~nm}$ from discrete water samples taken at $5 \mathrm{~m}$ (a) and mid-depth (b). The markers are colored by year and shaded by longitude as in Fig. 1. The system is CDOM dominated, especially near the surface; phytoplankton contributed more than $50 \%$ in only two cases for the entire dataset. 

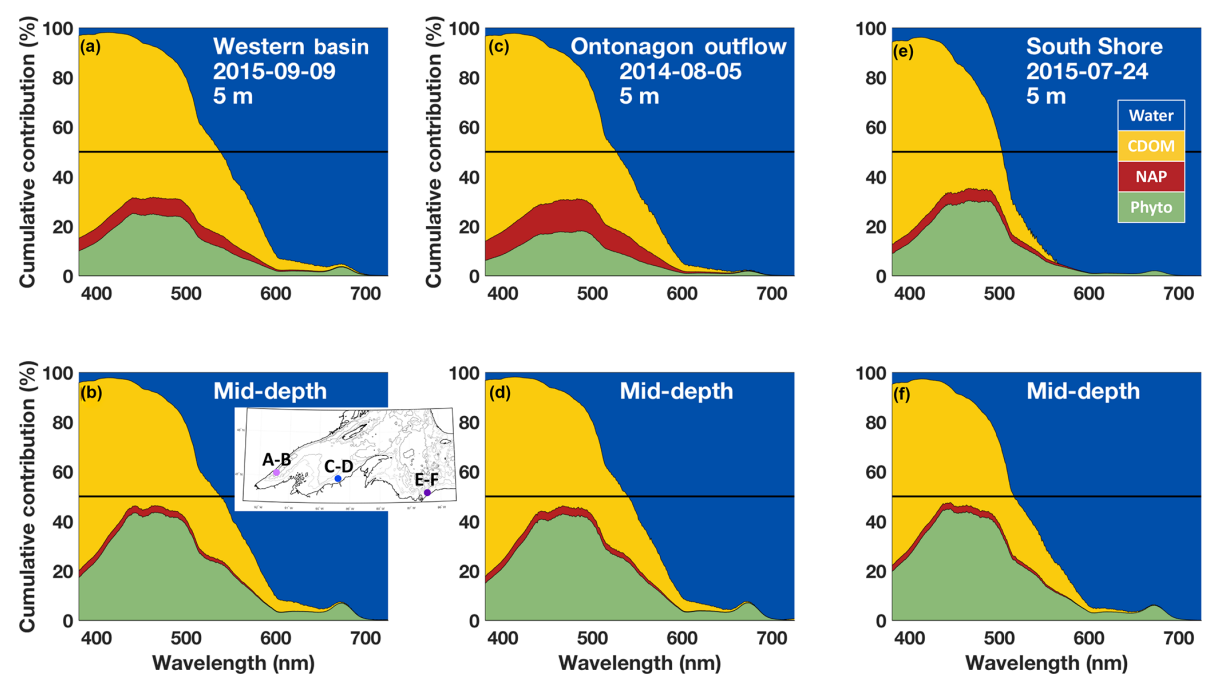

Figure 5. Spectrally resolved contribution of water, CDOM, non-algal particles, and phytoplankton to total absorption for discrete water samples taken at $5 \mathrm{~m}(\mathbf{a}, \mathbf{c}, \mathbf{e})$ and at mid-depth (b, d, f) from the western basin (a, b; light purple marker on map inset in b), Ontonagon River outflow (c, d; blue marker on map), and the South Shore (e, f; dark purple marker on map) of Lake Superior in the summer of 2014-2015. The black lines indicate a $50 \%$ cumulative contribution for visual reference.
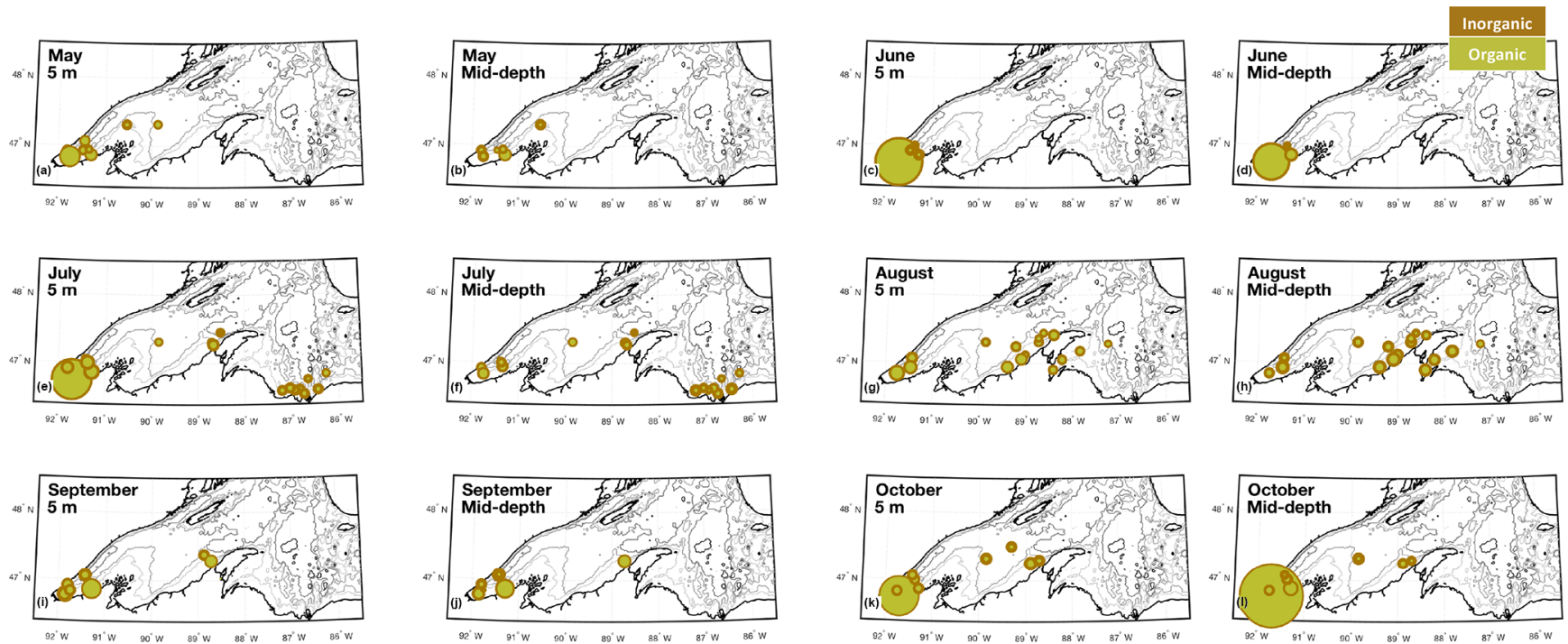

Figure 6. Suspended particulate matter for discrete water samples taken at $5 \mathrm{~m}$ and mid-depth for the Lake Superior dataset grouped by month. The outer diameter of each station marker indicates total SPM with the concentric circles representing the relative contributions of organic and inorganic components.

(Fig. 6). The high volumes of spring melt also delivered or stimulated growth, resulting in high $\mathrm{SPM}_{\mathrm{o}}$ in June. By July, freshwater entering the lake from the river was warm enough to cause a density gradient, at which the warm river water sat on top of the colder lake water; thus, SPM was significantly lower at the mid-depth. In August, SPM magnitude was relatively similar across the lake and between surface and mid-depth, but $\mathrm{SPM}_{\mathrm{i}}$ contributed a greater proportion of SPM at depth. By September and October, the depth distributions of $\mathrm{SPM}_{\mathrm{i}}$ and $\mathrm{SPM}_{\mathrm{o}}$ were similar, but the magnitude of SPM in the western arm was much greater in October due to runoff and water column mixing from fall storms. At this time of year, the riverine water cools faster than the lake, resulting in a submerged river plume; thus the greatest SPM was observed in the mid-depth.

In addition to the discrete measurements, in situ profiles of $a_{\mathrm{p}}(\lambda), a_{\mathrm{CDOM}}(\lambda)$ and $b_{\mathrm{bp}}(\lambda)$ were collected. Figure 7 displays examples of these spectral data for the same three stations as in Fig. 5. The St. Louis River inflow in the western basin was seen in $a_{\mathrm{p}}(\lambda)$ in the surface of the water column 

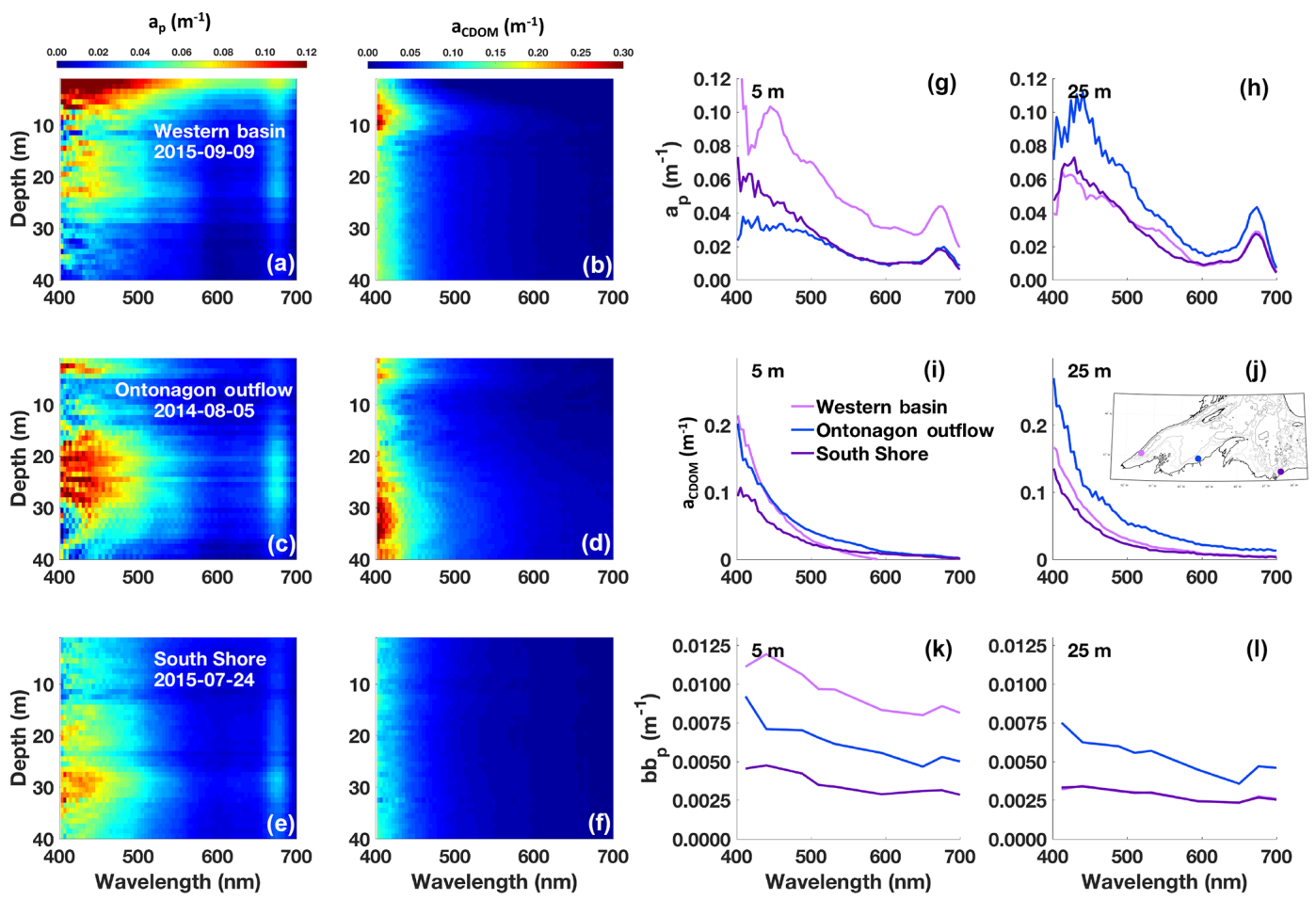

Figure 7. In situ IOP for select stations throughout Lake Superior in the summer of 2014 and 2015 (see inset map in j). Profiles of $a_{\mathrm{p}}(\lambda)(\mathbf{a}, \mathbf{c}, \mathbf{e})$ and $a_{\mathrm{CDOM}}(\lambda)(\mathbf{b}, \mathbf{d}, \mathbf{f})$ for the western basin $(\mathbf{a}, \mathbf{b})$, Ontonagon River outflow (c, d), and South Shore (e, f). Note the different color scales for the $a_{\mathrm{p}}(\lambda)$ and $a_{\mathrm{CDOM}}(\lambda)$ profiles. Examples of individual spectra at 5 and $25 \mathrm{~m}$ are shown in (g)-(j) along with in situ particulate backscattering $(\mathbf{k}, \mathbf{l})$. Data are binned to $1 \mathrm{~m}$.

(Fig. 7a) and the DCM at mid-depth. The presence of the phytoplankton in $a_{\mathrm{p}}(\lambda)$ was evidenced by a secondary spectral peak near $683 \mathrm{~nm}$. Riverine impact was also seen where $a_{\mathrm{CDOM}}(\lambda)$ was elevated in the near-surface waters but slightly deeper than $a_{\mathrm{p}}(\lambda)$ due to CDOM photobleaching (Fig. 7b). In the Ontonagon outflow, the riverine signal was also seen in $a_{\mathrm{p}}(\lambda)$ and $a_{\mathrm{g}}(\lambda)$, with a large deep chlorophyll contribution to $a_{\mathrm{p}}(\lambda)$ at mid-depth. Below the deep chlorophyll layer, $a_{\mathrm{CDOM}}(\lambda)$ was elevated, possibly from bloom degradation and sinking (Fig. 7c and d). Along the South Shore, there was no significant riverine source; thus $a_{\mathrm{p}}(\lambda)$ was low in the surface and high at depth associated with the DCM. Throughout the water column, $a_{\mathrm{CDOM}}(\lambda)$ was uniform and significantly lower than the riverine-impacted sites (Fig. 7e and f). Spectra were extracted from the profiles at $5 \mathrm{~m}$ and $25 \mathrm{~m}$ to show an alternative view of the spectral site comparison. Given the low contribution of $a_{\mathrm{NAP}}(\lambda)$ to the overall absorption budget (Fig. 5), variability in the spectral shape of in situ $a_{\mathrm{p}}(\lambda)$ could generally be attributed to differences in the phytoplankton community between the three locations (Fig. $7 \mathrm{~g}$ and $\mathrm{h}$ ). The most distinct difference was the presence of a peak at green wavelengths (centered at $550 \mathrm{~nm}$ ) for the location in the western basin, which was not present at the other two sites. The variability in the slope of $a_{\mathrm{CDOM}}(\lambda)$ was related to the molecular weight of the source carbon (Helms et al., 2008). The slopes of $a_{\mathrm{CDOM}}(\lambda)$ were slightly lower at $5 \mathrm{~m}$ than $25 \mathrm{~m}$, suggesting proportionately more terrestrial material in surface waters than water at depth (Fig. $7 \mathrm{i}$ and $\mathrm{j}$ ). The $b_{\mathrm{bp}}(\lambda)$ magnitude indicates the amount of particulate matter in the water, while the slope is related to the size of the particles, with steeper slopes associated with smaller particles (Reynolds et al., 2001). The magnitude of $b_{\mathrm{bp}}(\lambda)$ at $5 \mathrm{~m}$ was directly proportional to the particle delivery to that location, with the St. Louis River followed by the Ontonagon River outflow contributing significant particle loads. The $b_{\mathrm{bp}}(\lambda)$ of the western basin and the South Shore were nearly identical at $25 \mathrm{~m}$, suggesting a similar size of phytoplankton at these locations. The $b_{\mathrm{bp}}(\lambda)$ at the Ontonagon outflow at $25 \mathrm{~m}$ was higher and had a greater slope (Fig. $7 \mathrm{k}$ and 1 ) due to a greater abundance of phytoplankton (Figs. 1 and 2) and a different community composition.

Absorption and scattering processes impact the underwater light field and the light exiting the water column (i.e., $R_{\mathrm{rs}}(\lambda)$ ). $R_{\mathrm{rs}}(\lambda)$ is the parameter that a satellite radiometer observes. Figure 8 displays $R_{\mathrm{rs}}(\lambda)$ from in-water measurements at the surface, across all observation months, and light field variability with depth for the three stations also highlighted in Figs. 5 and 7. There were groups of similarly shaped $R_{\mathrm{rs}}(\lambda)$, with peaks near 490 or $570 \mathrm{~nm}$ and varying magnitudes (Fig. 8a-f). The magnitude of $R_{\mathrm{rs}}(\lambda)$ is re- 

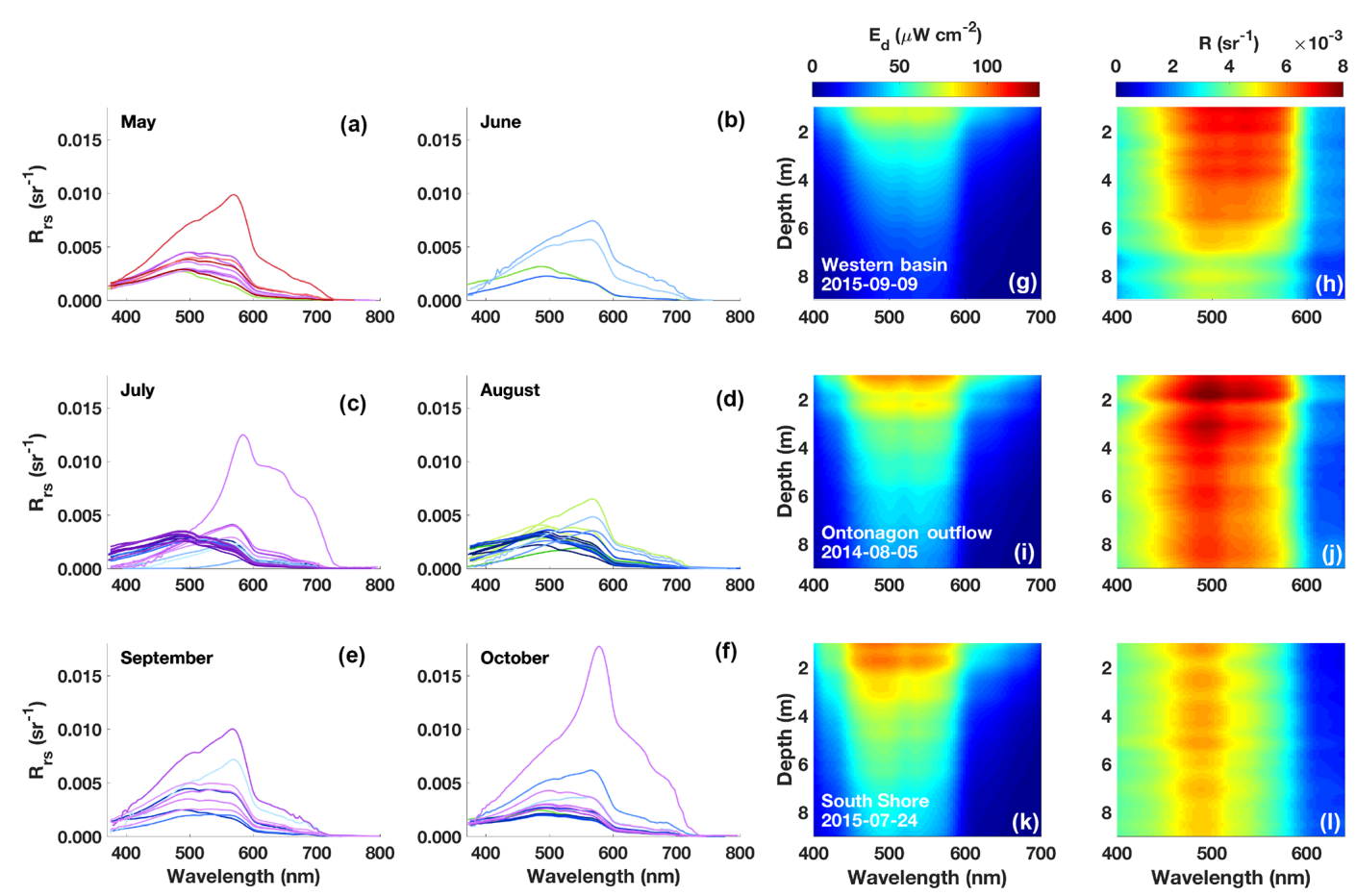

Figure 8. $R_{\mathrm{rs}}(\lambda)\left(=L_{\mathrm{W}}(\lambda) / E_{\mathrm{S}}(\lambda)\right)$ retrieved from combined near-surface multi-cast AOP profiles (a-f). The spectra are colored by year and shaded by longitude as in Fig. 1. Example spectral multi-cast AOP profiles for downwelling irradiance $\left(E_{\mathrm{d}}(\lambda)\right)$ and reflectance $\left(R(\lambda)=L_{\mathrm{u}}(\lambda) / E_{\mathrm{d}}(\lambda)\right)$ for the three locations from Figs. 5 and 7 (g-l).

lated to particulate abundance. The shape of $R_{\mathrm{rs}}(\lambda)$ is primarily related to the variations in the relative contributions and composition of phytoplankton, NAP, and CDOM. The spectra with the highest $R_{\mathrm{rs}}(\lambda)$ were found in the St. Louis River outflow. The underwater light field also varies spectrally depending on the abundance and type of optical constituents. The spectrally dependent depth of light penetration (i.e., $\left.E_{\mathrm{d}}(\lambda)\right)$ and the spectral light at depth (ratio of $L_{\mathrm{u}}(\lambda)$ to $\left.E_{\mathrm{d}}(\lambda)\right)$ showed significant variability across the three example sites (Fig. 8g-1). The least amount of light was available in the western basin with most available light at $510 \mathrm{~nm}$, while light penetrates the deepest near the South Shore and the most available light is at $490 \mathrm{~nm}$. The diffuse attenuation coefficient at $490 \mathrm{~nm}\left(K_{\mathrm{d}}(490)\right)$ was mapped to show geographic variability (Fig. 9). The shortest attenuation lengths (highest $K_{\mathrm{d}}(490)$ ) were found in the western basin; the greatest lengths were found in the central basin away from land in August.

While we followed widely accepted standard protocols here, as with any observations, there are always limitations to the approach. We used laboratory and in situ fluorometric measurements of chlorophyll concentration. While fluorometric observations are widely used, these measurements are subject to larger measurement errors than highperformance liquid chromatography (HPLC) chlorophyll analyses (Van Heukelem et al., 2002). However, we did not have access or resources to carry out HPLC measurements for these samples. Sosik (1999) evaluated the storage of particulate absorption samples prior to their analysis. She found that storage in liquid nitrogen was the most reliable, while storage at $-80^{\circ} \mathrm{C}$ was also satisfactory. However, increases in absorption were noted at ultraviolet wavelengths under all storage conditions. Thus, it is ideal to run particulate absorption analysis immediately after sampling; however, this was not practical for our field sampling. Stramski et al. (2015) evaluated the methods of transmittance (T), transmissionreflection (T-R; used here), and integrating sphere (IS) for measuring filter-pad particulate absorption. They ranked the superiority of these methods in descending order as follows: IS, T-R, and T. At the time of this analysis, we only had access to a $60 \mathrm{~mm}$ integrating sphere that did not allow for IS measurements, and this method is not yet widely used.

\section{Data availability}

The dataset contains coincident observations of total, particulate, phytoplankton, and CDOM absorption, total scatting, total and particulate backscattering, attenuation, remote sensing reflectance, chlorophyll concentration, and total suspended matter from 106 stations collected between 2013 and 2016. The compiled data are available from the National Aeronautics and Space Administration SeaWiFS Bio-optical Archive and Storage System (SeaBASS): https://seabass. 

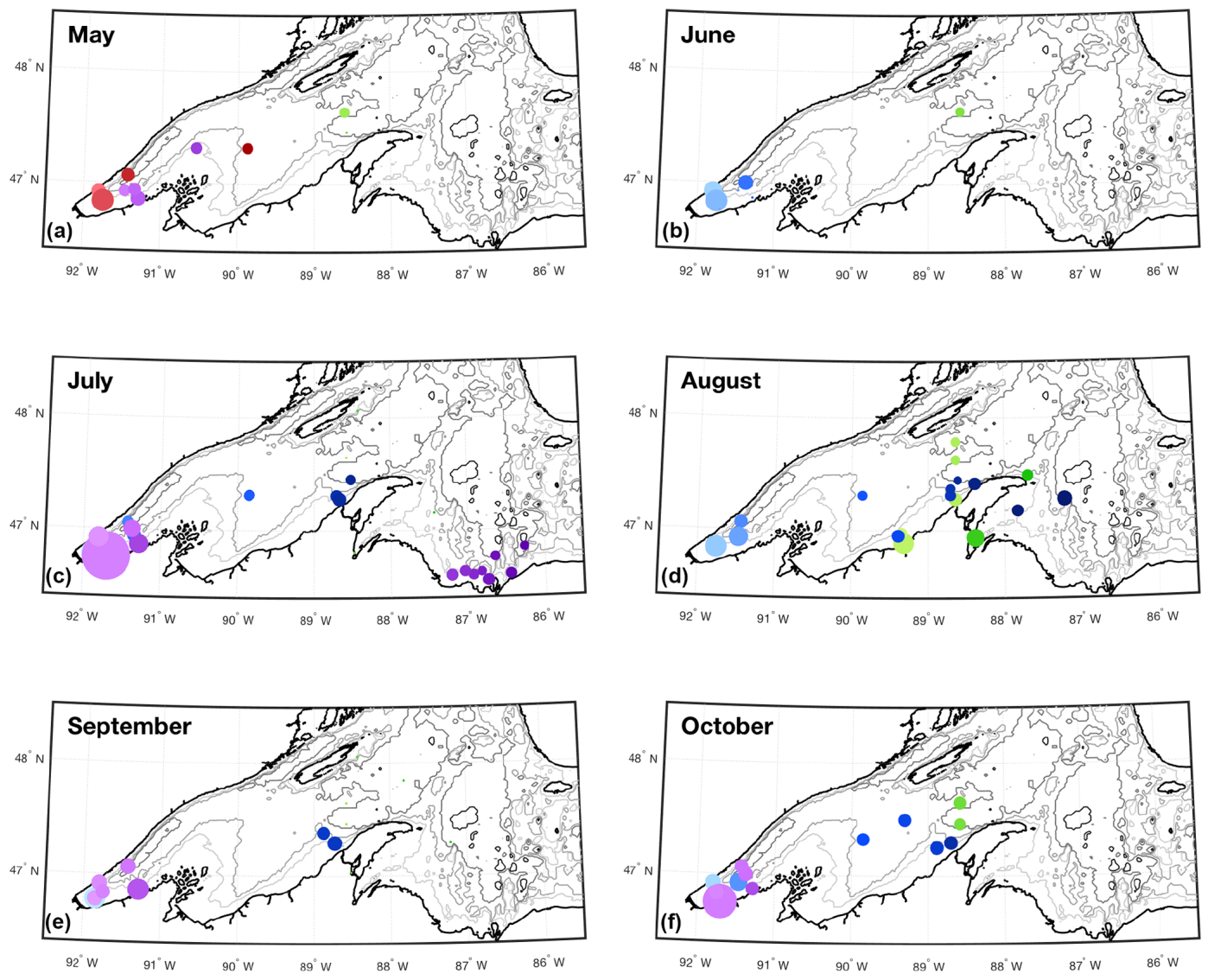

Figure 9. $K_{\mathrm{d}}(490)\left(\mathrm{m}^{-1}\right)$ for the Lake Superior dataset grouped by month. The stations are colored by year and shaded by longitude as in Fig. 1.

gsfc.nasa.gov/archive/URI/Mouw/LakeSuperior/ (Mouw et al., 2017).

\section{Conclusions}

This dataset has increased the number of coincident optical observations in Lake Superior from 8 observed in July 2006 (Effler et al., 2010) to 106 stations sampled during the icefree season (May through October) from 2013 to 2016. In addition to greatly expanding the temporal resolution of available data, the spatial (geographic and depth) distribution has grown to cover the western basin, the central lake, and the southern shore of the eastern basin. In a system that is challenging to observe with direct methods for half the year due to prolonged winter conditions, remote sensing is an important tool. The data presented here are essential for remote sensing algorithm development and validation and this dataset will go a long way toward improving and ensuring that quality scientific satellite products are produced for the interpretation of lake processes. Additionally, this dataset is valuable for characterizing the variable light field, particle, phytoplankton, and colored dissolved organic matter distri- butions, and helpful in food web and carbon cycle investigations.

Author contributions. Colleen B. Mouw designed the sampling and secured resources for the purchase of the optical instrumentation and funding to support the effort. Audrey B. Ciochetto maintained the optical instrumentation throughout the project period and quality controlled and achieved the dataset. While all authors contributed to the fieldwork to collect the observations, Brice Grunert and Audrey B. Ciochetto were responsible for the greatest amount of fieldwork. Audrey B. Ciochetto oversaw the laboratory sample analysis, processed all data, and prepared figures. Colleen B. Mouw prepared the paper with contributions from all co-authors.

Competing interests. The authors declare that they have no conflict of interest.

Acknowledgements. Funding for this project came from NASA (grant NNX14AB80G). The assistance of John Trochta, Rebekka Guyon, Benjamin Kramka, Jason Jakary, and Daniel Barton is acknowledged for field support and laboratory sample process- 
ing. Stephen Roblee, captain of the R/V Agassiz, is gratefully acknowledged along with the captain and crew of the $\mathrm{R} / \mathrm{V}$ Blue Heron. The faculty of the Large Lake Observatory at the University of Minnesota Duluth and support from the Legislative-Citizen Commission on Minnesota Resources are acknowledged for providing the opportunity to collect data aboard the R/V Blue Heron. Conversations with Gary Fahnenstiel were helpful to determine sampling strategy.

Edited by: Giuseppe M. R. Manzella

Reviewed by: Steven E. Lohrenz and one anonymous referee

\section{References}

APHA/AWWA/WEF - American Public Health Association, American Water Works Association and Water Environment Federation: Standard Methods for the Examination of Water and Wastewater, in: 21st Edn., Sections 2540A Solids, 2540C Total Suspended Solids Dried at $103-105^{\circ} \mathrm{C}$ and 2540 E Fixed and Volatile Solids Ignited at $550^{\circ} \mathrm{C}$, Washington, D.C., 2005.

Assel, R. A.: Fall and winter thermal structure of Lake Superior, J. Great Lakes Res., 12, 251-262, https://doi.org/10.1016/S03801330(86)71725-5, 1986.

Austin, J. A. and Allen, J.: Sensitivity of summer Lake Superior thermal structure to meteorological forcing, Limnol. Oceanogr., 56, 1141-1154, 2011.

Austin, J. A. and Colman, S. M.: Lake Superior summer water temperatures are increasing more rapidly than regional air temperatures: A positive ice-albedo feedback, Geophys. Res. Lett., 34, L06604, https://doi.org/10.1029/2006GL029021, 2007.

Barbiero, R. P. and Tuchman, M. L.: Results from the U.S. EPA's biological open water surveillance program of the Laurentian great lakes: I. Introduction and Phytoplankton Results, J. Great Lakes Res., 27, 134-154, 2001.

Barbiero, R. P. and Tuchman, M. L.: The Deep Chlorophyll Maximum in Lake Superior, J. Great Lakes Res., 30, 256-268, https://doi.org/10.1016/S0380-1330(04)70390-1, 2004.

Binding, C. E., Jerome, J. H., Bukata, R. P., and Booty, W. G.: Spectral absorption properties of dissolved and particulate matter in Lake Erie, Remote S. Environ., 112, 1702-1711, https://doi.org/10.1016/j.rse.2007.08.017, 2008.

Boss, E., Taylor, L., Gilbert, S., Gundersen, K., Hawley, N., Janzen, C., Johengen, T., Purcell, H., Robertson, C., Schar, D. W. H., Smith, G. J., and Tamburri, M. N.: Comparison of inherent optical properties as a surrogate for particulate matter concentration in coastal waters, Limnol. Oceanogr. Meth., 7, 803-810, 2009.

Budd, J. and Warrington, D.: Satellite-based sediment and chlorophyll a estimates for Lake Superior, J. Great Lakes Res., 30, 459466, https://doi.org/10.1016/S0380-1330(04)70406-2, 2004.

Dierssen, H. M.: Perspectives on empirical approaches for ocean color remote sensing of chlorophyll in a changing climate, P. Natl. Acad. Sci. USA, 107, 17073-17078, https://doi.org/10.1073/pnas.0913800107, 2010.

Effler, S. W., Perkins, M., Peng, F., Strait, C., Weidemann, A. D., and Auer, M. T.: Light-absorbing components in Lake Superior, J. Great Lakes Res., 36, 656-665, https://doi.org/10.1016/j.jglr.2010.08.001, 2010.

Helms, J., Stubbins, A., Ritchie, J., Minor, E., Kieber, D., and Mopper, K.: Absorption spectral slopes and slope ratios as indica- tors of molecular weight, source, and photobleaching of chromophoric dissolved organic matter, Limnol. Oceangr., 53, 955969, 2008.

Hubbs, C. L. and Lagler, K. F.: Fishes of the Great Lakes region, revised Edn., edited by: Smith, G. R., University of Michigan Press rev., Michigan, 2004.

Lee, Z., Carder, K., and Arnone, R.: Deriving inherent optical properties from water color: a multiband quasi-analytical algorithm for optically deep waters, Appl. Optics, 41, 5755-5772, 2002.

Lenters, J. D.: Trends in the Lake Superior water budget since 1948: a weakening seasonal cycle, J. Great Lakes Res., 30, 20-40, 2004.

Li, H., Budd, J. W., and Green, S.: Evaluation and regional optimization of bio-optical algorithms for Central Lake Superior, J. Great Lakes Res., 30, 443-458, 2004.

Lohrenz, S. E.: A novel theoretical approach to correct for pathlength amplification and variable sampling loading in measurements of particulate spectral absorption by the quantitative filter technique, J. Plank. Res., 22, 639-657, 2000.

Lohrenz, S. E., Weidemann, A. D., and Tuel, M.: Phytoplankton spectral absorption influenced by community size structure and pigment composition, J. Plank. Res., 25, 35-61, 2003.

Mason, L. A., Riseng, C. M., Gronewold, A. D., Rutherford, E. S., Wang, J., Clites, A., Smith, S. D. P., and McIntyre, P. B.: Fine-scale spatial variation in ice cover and surface temperature trends across the surface of the Laurentian Great Lakes, Climatic Change, 138, 71-83, https://doi.org/10.1007/s10584-016-17212, 2016.

Matheson, D. H. and Munawar, M.: Lake Superior Basin and its development, J. Great Lakes Res., 4, 249-263, 1987.

Mitchell, B. G., Kahru, M., Wieland, J., and Stramska, M.: Determination of spectral absorption coefficients of particles, dissolved material and phytoplankton for discrete water samples, in: Ocean optics protocols for satellite ocean color sensor validation, revision 4, vol. IV: Inherent Optical Properties: Instruments, characterizations, field measurements and data analysis protocols, NASA/TM-2003-211621/Rev4-Vol. IV, edited by: Mueller, J. L. and Fargion, G. S., National Aeronautical and Space Administration, Goddard Space Flight Space Center, Greenbelt, Maryland, 76 pp., 2003.

Mobley, C. D.: Light and Water: Radiative Transfer in Natural Waters, Academic, San Diego, California, 592 pp., 1994.

Mouw, C. B., Chen, H., McKinley, G. A., Effler, S., O’Donnell, D., Perkins, M. G., and Strait, C.: Evaluation and optimization of bio-optical inversion algorithms for remote sensing of Lake Superior's optical properties, J. Geophys. Res.-Oceans, 118, 16961714, https://doi.org/10.1002/jgrc.20139, 2013.

Mouw, C. B., Greb, S., Aurin, D., DiGiacomo, P. M., Lee, Z., Twardowski, M., Binding, C., Hu, C., Ma, R., Moore, T., Moses, W., and Craig, S. E.: Aquatic color radiometry remote sensing of coastal and inland waters: Challenges and recommendations for future satellite missions, Remote Sens. Environ., 160, 15-30, https://doi.org/10.1016/j.rse.2015.02.001, 2015.

Mouw, C. B., Ciochetto, A. B., Grunert, B., and Yu, A.: LakeSuperior, SeaWiFS Bio-optical Archive and Storage System (SeaBASS), NASA, https://seabass.gsfc.nasa.gov/archive/ URI/Mouw/LakeSuperior/, last access: 6 January 2017.

Mueller, J. L., Fargion, G. S., and McClain, C. R.: Ocean optics protocols for satellite ocean color sensor validation, in: revision 
4, vol. III: Radiometric Measurements and Data Analysis protocols, NASA/TM-2003-21621/Rev4-Vol.III, National Aeronautical and SpaceAdministration, Goddard Space Flight Space Center, Greenbelt, Maryland, 84 pp., 2003a.

Mueller, J. L., Fargion, G. S., and McClain, C. R.: Ocean optics protocols for satellite ocean color sensor validation, in: revision 4, vol. IV: Inherent Optical Properties: Instruments, characterizations, field measurements and data analysis protocols, NASA/TM-2003-211621/Rev4-Vol. IV, National Aeronautical and Space Administration, Goddard Space Flight Space Center, Greenbelt, Maryland, 76 pp., 2003 b.

Munawar, M. and Munawar, I. F.: Phytoplankton of Lake Superior, J. Great Lakes Res., 4, 415-442, 1973.

O’Donnell, D. M., Effler, S. W., Strait, C. M., Peng, F., and Perkins, M.: Remote sensing reflectance in the Great Lakes: In situ measurements, closure analyses, and a forward model, J. Great Lakes Res., 39, 137-150, https://doi.org/10.1016/j.jglr.2013.06.016, 2013.

O'Reilly, C. M., Sharma, S., Gray, D. K., et al.: Rapid and highly variable warming of lake surface waters around the globe, Geophys. Res. Lett., 42, 10773-10781, https://doi.org/10.1002/2015GL066235, 2015.

Peng, F., Effler, S., O’Donnell, D., Weidemann, A., and Auer, M.: Characterizations of minerogenic particles in support of modeling light scattering in Lake Superior through a two-component approach, Limnol. Oceanogr., 54, 1369-1381, 2009.

Pope, R. M. and Fry, E. S.: Absorption spectrum (380-700 nm) of pure water. II. Integrating cavity measurements, Appl. Optics, 18, 8710-8723, 1997.

Porra, R. J.: A simple method for extracting chlorophylls from the recalcitrant alga, Nannochloris atomus, without formation of spectroscopically different magnesium-rhodochlorin derivatives, Biochim. Biophys. Ac.-Bioenerg., 1019, 137-141, https://doi.org/10.1016/0005-2728(90)90135-Q, 1990.

Reynolds, R., Stramski, D., and Mitchell, B.: A chlorophylldependent semianalytical reflectance model derived from field measurements of absorption and backscattering coefficients within the Southern Ocean, J. Geophys. Res., 106, 7125-7138, 2001.

Smith, R. C. and Baker, K. S.: Analysis of ocean optical data, in: Ocean Optics VII, edited by: Blizard, M., SPIE, 478, 119-126, 1984.

Smith, R. C. and Baker, K. S.: Analysis of ocean optical data, in: Ocean Optical VIII, edited by: Slater, P. N., SPIE, 637, 95-107, 1986.

Sosik, H.: Storage of marine particulate samples for lightabsorption measurements, Limnol. Oceanogr., 44, 1139-1141, 1999.

Stramski, D., Reynolds, R. A., Kaczmarek, S., Uitz, J., and Zheng, G.: Correction of pathlength amplification in the filter-pad technique for measurements of particulate absorption coefficient in the visible spectral region, Appl. Optics, 54, 6763-6782, 2015.
Sterner, R. W.: In situ-measured primary production in Lake Superior, J. Great Lakes Res., 36, 139-149, 2010.

Sterner, R. W.: C : N : P stoichiometry in Lake Superior: freshwater sea as end member, Inland Waters, 1, 29-46, 2011.

Sullivan, J. M., Twardowski, M. S., Zaneveld, J. R. V., Moore, C. M., Barnard, A. H., Donaghay, P. L., and Rhoades, B.: Hyperspectral temperature and salt dependencies of absorption by water and heavy water in the $400-750 \mathrm{~nm}$ spectral range, Appl. Optics, 45, 5294-5309, 2006.

Sullivan, J. M., Twardowski, M. S., Zaneveld, J. R. V., and Moore, C. C.: Measuring optical backscattering in water, in: Light Scattering Reviews 7: Radiative Transfer and Optical Properties of Atmosphere and Underlying Surface, Springer Praxis Books, chap. 6, edited by: Kokhanovsky, A. A., Springer, Heidelberg, 189-224, https://doi.org/10.1007/978-3-642-21907-8_6, 2013.

Tassan, S. and Ferrari, G. M.: A sensitivity analysis of the "Transmittance-Reflectance" method for measuring light absorption by aquatic particles, J. Plank. Res., 24, 757-774, 2002.

Trees, C. C., Bidigare, R. R., Karl, D. M., Heukelem, L. V., and Dore, J.: Fluorometeric chlorophyll $a$ : sampling, laboratory methods and data analysis protocols, in: Ocean Optics Protocols for Satellite Ocean Color Sensor Validation, Revision 5, Vol. V: Biogeochemical and Bio-optical measurements and data analysis protocols, chap. 3, NASA/TM-2003-211621, edited by: Mueller, J. L., Fargion, G. S., and McClain, C. R., NASA Goddard Space Flight Center, Greenbelt, MD, 15-25, 2003.

Trochta, J. T., Mouw, C. B., and Moore, T. S.: Remote sensing of physical cycles in Lake Superior using a spatio-temporal analysis of optical water typologies, Remote Sens. Environ., 171, 149161, https://doi.org/10.1016/j.rse.2015.10.008, 2015.

Van Heukelem, L., Thomas, C. S., Gilbert, P. M., Fargion, G. S., and McClain, C. R.: Sources of variability in chlorophyll analysis by fluorometry and high-performance liquid chromatography in a SIMBIOS inter-calibration exercise, NASA/TM-2002-211606, NASA, Greenbelt, MD, 2002.

Weller, R. R.: Chemistry of Lake Superior, J. Great Lakes Res., 4, 370-385, 1978.

Woźniak, S. B., Meler, J., Lednicka, B., Zdun, A., and StońEgiert, J.: Inherent optical properties of suspended particulate matter in the southern Baltic Sea, Oceanologia, 53, 691-729, https://doi.org/10.5697/oc.53-3.691, 2011.

Zaneveld, J. R. V., Kitchen, J. C., and Moore, C.: The scattering error correction of reflecting-tube absorption meters. Ocean Optics XII, Proc. SPIE, 2258, 44-55, 1994.

Zhang, X. and Hu, L.: Estimating scattering of pure water from density fluctuations of the refractive index, Opt. Express, 17, 16711678, 2009. 